\title{
Health Implications of Climate Change: a Review of the Literature About the Perception of the Public and Health Professionals
}

\author{
Julia Hathaway ${ }^{1} \cdot$ Edward W. Maibach ${ }^{1}$ \\ Published online: 8 February 2018 \\ (C) The Author(s) 2018. This article is an open access publication
}

\begin{abstract}
Purpose of Review Through a systematic search of English language peer-reviewed studies, we assess how health professionals and the public, worldwide, perceive the health implications of climate change.

Recent Findings Among health professionals, perception that climate change is harming health appears to be high, although selfassessed knowledge is low, and perceived need to learn more is high. Among the public, few North Americans can list any health impacts of climate change, or who is at risk, but appear to view climate change as harmful to health. Among vulnerable publics in Asia and Africa, awareness of increasing health harms due to specific changing climatic conditions is high. Americans across the political and climate change opinion spectra appear receptive to information about the health aspects of climate change, although findings are mixed.
\end{abstract}

Summary Health professionals feel the need to learn more, and the public appears open to learning more, about the health consequences of climate change.

Keywords Climate change $\cdot$ Climatic change $\cdot$ Health $\cdot$ Public health $\cdot$ Perceptions $\cdot$ Attitudes $\cdot$ Opinions

\section{Introduction}

As stated in the introduction to the most recent US National Climate Assessment, "Climate change, once considered an issue for a distant future, has moved firmly into the present" [1]. The current impacts of climate change include increases in certain types of extreme weather (e.g., heat waves, heavy precipitation) and climatic events (droughts), increased water and food insecurity, rising sea levels and ocean acidification, damage to ecosystems and biodiversity, damage to societal

This article is part of the Topical Collection on Climate Change and Health

Electronic supplementary material The online version of this article (https://doi.org/10.1007/s40572-018-0190-3) contains supplementary material, which is available to authorized users.

Edward W. Maibach emaibach@gmu.edu

Julia Hathaway

Jhathaw3@gmu.edu

1 Center for Climate Change Communication, George Mason University, 4400 University Drive, MS 6A8, Fairfax, VA 22030, USA infrastructures, and most directly germane to this article, a range of direct and indirect harms to human health [1-3].

The US Climate and Health Assessment identified seven major categories of health impacts from climate change, including increased morbidity and mortality from increasing extreme temperatures; temporary reductions in air quality from smog and smoke; increases in extreme weather and climatic events; increasing vector-borne diseases; increasing water-related illness; decreasing food safety, nutrition, and distribution; and mental health conditions including anxiety, depression, and substance use. While anyone's health can be harmed by climate change, some people are at greatly increased risk including young children, pregnant women, older adults, people with chronic illnesses and disabilities, outdoor workers, and people with fewer resources [3]. Some of these health impacts are just now emerging, but others have been harming the public's health for years [4].

Although much remains to be learned about the impacts of climate change on human health, the fact that climate change is a major public health threat has been observed by local communities around the world and has been well documented by climate and health experts $[1-3,5 \bullet \bullet, 6]$. Indeed, climate change is seen by some experts as "the biggest global health threat of the 21 st century" [7]. The extent to which the general 
public and practicing health professionals-including clinical and population health professionals - around the world are aware of the health relevance of climate change, however, is unclear. Therefore, we conducted a systematic literature review to answer three research questions focused on health professional and public understanding of the human health relevance of climate change:

1. How do health professionals perceive the health implications of climate change?

2. How does the public perceive the health implications of climate change?

3. How does the public react to information about the health implications of climate change?

Furthermore, we stratified the review into two linguistically defined geographies: English-speaking nations and nonEnglish-speaking nations.

\section{Methods}

We used an iterative search process to locate research for consideration and review. First, between February 8 and February 22, 2017, we searched Google Scholar utilizing search terms "climate change," "climatic change," "health," "public health," "perceptions," "attitudes," and "opinions." The search period covered all publications available by March 2, 2017. Between February 22 and March 2, 2017, we searched Medline, Global Health, Psych Info, Web of Science, GreenFILE, and Communication and Mass Media Complete, using mesh terms "perceptions and attitudes" and "perceptions and attitudes and opinions" with "climate change" or "climatic change" and "health" or "public health" where possible. Concurrently, we requested citations from some authors who publish in this area and posted a similar request to a relevant listserv (International Environmental Communication Association).

With one exception (a nationally representative poll conducted by our research team that contained unique relevant information [8]), only English language, peer-reviewed studies were included in the review. Additional exclusion criteria were the following: research done on convenience samples (except in the case of in-depth interview studies, for which convenience samples are appropriate); inadequate information provided on survey response rate; and focus group research (due to concerns about validity of such data [9]).

Research questions were as follows:

RQ1: How do health professionals perceive the health impacts of climate change?

RQ2: How does the public perceive the health impacts of climate change?
RQ3: How does the public react to information about the health implications of climate change?

English-speaking countries included Australia, Canada, the UK, and the USA. One 24-nation study also included New Zealand [10].

A brief summary of each study identified was prepared; these are included in a Supplement for this article. From those summaries, the following results were synthesized.

\section{Results}

RQ1: How do health professionals perceive the health impacts of climate change?

\section{English-Speaking Nations}

We identified a total of 12 studies conducted with health professionals in English-speaking nations: seven with public health department personnel (six in the USA [11-16] and one in Canada [17]), four with physicians (three in the USA [18-20] and one in Australia [21]), and one with dieticians in the USA [22]. On the whole, a large majority of both clinical and population health professionals with whom research has been conducted understand that climate change is occurring, and that it is already harming or has the potential to cause harm to the public's health in the near future.

In health departments, different groups of professionalsspecifically directors, environmental health directors, and nursing directors - appear to have largely similar views of the public health relevance of climate change, but some differences are evident both within and between groups.

Most public health department directors see climate change a potentially serious public health problem in their jurisdiction, although this is not universally the case. In 2008, a majority (69\%) of American local public health department directors perceived climate change to be occurring in their jurisdiction - whereas only $11 \%$ did not—while $78 \%$ felt their jurisdiction would experience climate change over the next 20 years [11]. However, a 2012 replication of the 2008 study found that polarization may have occurred, with most directors becoming more certain that climate change is already occurring in their jurisdiction (an increase of 9.3\%), while other directors became more certain it is not happening in their jurisdiction (an increase of $11.3 \%$ ); the proportion who were not sure either way had declined [16].

Similarly, by 2012 , more directors had become more certain that over the next 20 years, their jurisdiction would experience one or more serious public health problems as a result of climate change (an increase of $17.8 \%$ ), while more directors also became more certain their jurisdiction would not (an increase of $9.3 \%$ ). Two state-based surveys of health department directors showed divergent profiles: in 2008 , nearly all 
directors in California (94\%) perceived climate change to be a threat to public health [12], whereas in 2009, only a minority of directors in New York State $(32 \%)$ perceived climate change to be occurring yet in their jurisdiction [13].

Most environmental health directors nationwide feel that climate change will have serious health impacts globally $(65 \%)$ and in the USA $(56 \%)$; however, fewer than half $(46 \%)$ believe their jurisdiction will experience serious impacts [14]. Similarly, nearly all public health nursing directors nationwide $(90 \%)$ perceive that human-caused climate change is happening (90\%), and most (65\%) feel its health-related impacts will be a serious public health issue in the next 20 years [15].

The specific public health risks of greatest concern to public health personnel appear to be heat-related impacts, displacements, disruptions in health care due to storms and floods, vector-borne illness, air quality-related conditions, and mental health problems $[11,12,14,17]$. Relatively few health departments have developed programs to address these problems, and most respondents indicated their department will need assistance (including expertise, additional people, and finances) to make significant progress [11-14, 16, 17].

Among physicians, a similar profile emerged. Most clinicians are convinced that climate change is happening and is already beginning to affect the health of some of their patients. Three physician surveys - of African-American physicians, thoracic specialists, and asthma and allergy specialists - all found that a sizable majority of respondents felt they had patients whose health was already being harmed by climate change in a variety of ways. The health impacts most commonly identified were air pollution-related increases in severity of chronic disease, such as asthma, COPD, and cardiovascular disease; allergic symptoms; heat-related effects; vector-borne illnesses; diarrheal diseases from food-/water-borne agents of infection; and injuries due to extreme weather [18-20].

Despite their experiences to date with health impacts of climate change, most physicians feel they lack knowledge about the topic, and large majorities support increased education on the health aspects of climate change in the form of continuing medical education, undergraduate medical education, patient education materials, and medical association policy statements. Large majorities also say that physicians and their associations should be involved in advocacy pertaining to the health effects of climate change [18-20].

\section{Non-English-Speaking Nations}

Six surveys of health professionals' perceptions of and knowledge about climate change have been done in non-Englishspeaking nations. They include Ethiopian health science students [23], Indian medical residents [24], Cambodian health professionals [25], Chinese hospital-based nurses [26], and Chinese public health professionals [27, 28]. In all cases, a large majority of respondents perceived that climate change is harmful to health, but their self-assessed knowledge was low, and their perceived need to learn more was high.

In addition, one study conducted in the European Economic Area, including all European Union countries as well as Norway, Iceland, and Lichtenstein, found that a large majority of national infectious disease experts agreed that climate change would affect vector-borne $(86 \%)$, food-borne $(70 \%)$, water-borne $(68 \%)$, and rodent-borne $(68 \%)$ diseases in their countries [29].

RQ2: How does the public perceive the health impacts of climate change?

\section{English-Speaking Nations}

Ten studies have been done to assess public understanding of the health impacts of climate change in English-speaking countries; most of this research has been conducted in Canada [30-33] and the USA [8, 11, 31, 34-36]. Overall, it appears that relatively few Canadians and Americans associate climate change and health harms; most report they have given little thought to the issue $[31,37]$. The depth of participants' knowledge and risk perceptions is difficult to assess because people's answers to open-ended questions give the impression of relatively little knowledge and risk perception [31, 34, 35, 38], whereas people's answers to closed-ended questions demonstrate much higher level of risk perception [31, 34, 35, 39]. Specifically, only a minority of survey participants answer open-ended questions in ways that suggest they know anything about how climate change harms health, or who is most likely to be harmed [11, 38]. However, when asked specific closed-ended questions, a majority of respondents answer in a manner indicating that they do perceive climate change to be harmful to health [31, 37].

There are at least two possible explanations for the discrepancy between people's answers to open-ended versus closedended answers about climate and health. One is that many people are more knowledgeable and perceive more risk than their open-ended responses suggest, but because the issue has low salience to them, specific health impacts and risk groups do not come to mind unless specifically prompted (by followon or closed-ended questions). Another possibility-made plausible by the fact that the majority of people surveyed hold negative views about global warming - is that many people do not have prior perceptions about the health relevance of climate change, but when asked closed-ended questions about the topic, they draw on their preexisting negative views about the issue in general to generate answers to specific questions about climate and health. Which explanation(s) best account for the discrepancy between the findings resulting from openended and closed-ended questions is not yet clear.

Another important finding is that in studies in the USA and UK, people have a strong tendency to see climate change as less threatening to their health and to their family's health than 
to other people's health-with escalating levels of health threat accorded to people in their community, to Americans in general, and to people worldwide $[8,36,40]$.

The one clear exception to finding that few people can identify specific health harms from climate change comes from a study of Inuit elders and seniors in Nunatsiavut, Canada. The majority of Inuits interviewed felt that climate change is harming their health through reduced physical activity (due to a shorter ice season), compromised nutrition (due to reduced catch of wild game), and increased stress and substance use [32].

In summary, a majority of people in Canada (except possibly Inuit elders) and the USA appear to know relatively little about the health impacts of climate change, but many hold negative views of the health impacts of climate change regardless, or they appear willing to accept that climate change is harmful to human health.

\section{Non-English-Speaking Nations}

Eight studies have assessed public understanding of the health harms associated with climate change in the non-Englishspeaking world. Three of these studies have been conducted in Africa (two in Tanzania and one in Nigeria [41-43]) and four in Asia (Bangladesh, Nepal, Tibet, and Vietnam) [43-46], with one additional study in Malta [31]. In all cases but one (Malta), this research has focused on especially vulnerable regions and populations.

Awareness of climate change per se tends to be low-with Hanoi, Vietnam serving as an exception (at approximately $75 \%$ [47]) - but all of the studies found very high rates of perceived changes in climatic conditions that are consistent with climate change, including changes in precipitation and temperature. All of the studies also show very high rates of awareness of health harms due to these changing climatic conditions. These include increases in food insecurity (Tanzania, Nigeria, Bangladesh $[42,43,48]$ ) and water insecurity (Nigeria, Bangladesh [43, 48]); illness (Malta, Nigeria, Nepal, Vietnam [31, 46-48]) and stress (Nigeria [48]); injuries from extreme weather events (Bangladesh [43]); and heat risk (Tibet [45]).

RQ3: How does the public react to information about the health implications of climate change?

Eleven studies have assessed public reactions to information about the health implications of climate change [10, 49-58]. All but one was done in American populations. The exception, a study conducted in 24 nations [10], included the following nations in addition to the USA: Australia, Brazil, Chile, China, France, Germany, Ghana, Iceland, Israel, Japan, Mexico, Netherlands, New Zealand, Norway, Poland, Russia, South Africa, South Korea, Spain, Sweden, Switzerland, Venezuela, and the UK. No firm conclusions can be reached, but some tentative conclusions seem defensible.
Americans across the political and climate change opinion spectra appear receptive to information about the health aspects of climate change [49-51]. Other studies, however, suggest limitations. One study found a small beneficial effects of providing health-framed climate information, but also found that the effect was neutralized by climate change denial counter-messaging [51]. Another found no differential impact of a health-framed message [52], and a third found positive effects for self-identified Democrats, but negative effects (i.e., a boomerang effect) among self-identified Republicans [53]. Conversely, one small study with people who were particularly vulnerable to the health impacts of climate change (based on their health and SES status) found that participants responded favorably to simple information about climate and health, becoming more certain that climate change is happening and that it may affect their health, and they gained knowledge about who is most vulnerable to such impacts [54].

One study - which examined how likely various types of information about climate change are to be shared from person to person - found that information about the health impacts of climate change was shared with greater frequency than information about several other types of climate impacts [55].

A small field study of homeowners found that information about the environmental and public health externalities of electricity production, such as childhood asthma and cancer, was more effective at motivating home energy-saving behavior than information about saving money, especially among households with children [56].

A series of studies conducted by Levine and Kline [57], however, provides a cautionary note. In three experimentsfield experiments and web-based experiments - they found that climate messages intended to make people concerned about their own health successfully heighten people's concerns about climate change, but paradoxically they also reduce people's rate of political participation (e.g., signing a petition, or joining a climate advocacy organization) to express their concern. The hypothesized mechanism of the paradoxical finding is that when people feel their material resources are threatened (in this case, their health), their response is to conserve their resources by avoiding additional commitments (presumably so as to better withstand resource constraints that may be forthcoming).

The only research conducted beyond the USA was a 24nation study of university students that also included community samples in 10 of the nations. Participants were not presented with information about climate and health, but rather were asked to imagine what their country will look like in the future - in 2050 - when people have taken action aimed at preventing climate change. They were then asked how much better, or worse, various conditions in their society would be at that time, including disease and pollution. Participants who believed that climate change action would reduce dysfunction in society, including realizing the health benefits of reducing disease, were significantly (albeit weakly) more likely to 
intend to perform climate change-relevant citizenship actions (e.g., contact an elected official) and household actions (e.g., install products to save energy) over the next 12 months, and to donate to an environmental organization [10].

\section{Conclusion}

Given the rapidly mounting evidence of the many current significant health risks posed by climate change [1-3, 6], our review makes clear the relative paucity of assessment research aimed at illuminating health professional and public understanding of these risks; we found only 46 English language peer-reviewed studies that addressed any of the three basic research questions that we posed. Informing, educating, and empowering populations at risk, and the health professionals who serve them, are an essential function of public health, and performing this function effectively requires assessment of what these key audiences already know [59]. Developing effective climate change adaptation programs that protect the public's health from increasingly extreme weather, climate variability, and other changing climatic conditions will require sustained professional and public education initiatives [60-64]. The far-reaching health effects of climate change have important implications for how nations build, organize, and manage health care systems [65], particularly in vulnerable communities and low-income countries where the worst effects will be felt.

Our conclusion from the sparse evidence reviewed is that many health professionals in North America and in some parts of Asia and Africa have at least basic awareness that climate change is a proximal and serious health threat to the public's health, and they are acutely aware of both their need to learn more about the risks and how to manage them; they are also aware of the need for additional resources - in the form of expertise, personnel, and financing - to mount effective population health responses.

Our conclusion about public awareness - again, based on sparse evidence - is that most residents of developed countries know little or nothing about the health relevance of climate change, but are open to learning such information, and are inclined to believe that it may be harmful to health. Conversely, most vulnerable residents of developing nations do appear to recognize that specific climatic conditions where they live are changing, and those changing conditions are causing deleterious health impacts, although most have not ever heard the terms global warming or climate change.

The news media can play an important role in informing the public - and health professionals - about the health implications of climate change. Historically, however, the issue has received little press attention. The overall amount of climate change news reporting has waxed and waned considerably over the past several decades, with more reporting occurring around major scientific (e.g., IPCC) and political (e.g., the
Paris Climate Agreement) events, but the total amount of climate reporting is a very small fraction of the total "news hole" (i.e., the total amount of news reported) - less than $1 \%$ worldwide [66]. In turn, climate and health stories are a small fraction of all climate news stories. In select American national and local newspapers, for example, the proportion of climate change stories that focus on climate and health stories has been shown to be in the range of 5 to $14 \%[67,68]$. Developing a sustained news media outreach strategy may provide a cost-effective basis for educating the public about climate change health risks and prevention options.

Finally, some health experts have called for efforts to heighten public engagement in limiting (i.e., mitigating) climate change by highlighting the health impacts of climate change [69] and the benefits of reducing greenhouse gas emissions $[60,70]$. Our conclusion from the studies reviewed for RQ3 is that there may be merit to this communication strategy. At least some evidence suggests that learning about the health relevance of climate change and climate solutions helps stimulate public engagement, particularly among vulnerable people and households, and conservatives. The largest study to examine this question to date-which was not included in our review (but is currently under review) - found that American adults who read brief essays about the eight categories of health impacts of climate change - as summarized from the National Climate and Health Assessment [3] - became more cognitively and affectively engaged in the issue of global warming, especially people with a chronic illness, and political moderates and conservatives. These findings are promising in that the health angle can bring new constituencies and perspective to local, state, and national policy discourses about climate change mitigation [71]. This would appear to be a promising area for further research.

It is worth noting that accelerating the transition away from fossil fuels and toward clean renewable energy is arguably the most important global action that can be taken to limit climate change and prevent its health consequences [1, $3,6]$. American polling research finds high public support for this proposition and finds that the robust public support for clean energy is largely driven the perception that clean energy sources are healthful energy sources $[72,73]$.

Acknowledgments Support for this study was provided by the Energy Foundation and ClimateWorks Foundation.

\section{Compliance with Ethical Standards}

Conflict of Interest The authors declare that they have no conflict of interest.

Human and Animal Rights and Informed Consent This article does not contain any studies with human or animal subjects performed by any of the authors. 
Open Access This article is distributed under the terms of the Creative Commons Attribution 4.0 International License (http:// creativecommons.org/licenses/by/4.0/), which permits unrestricted use, distribution, and reproduction in any medium, provided you give appropriate credit to the original author(s) and the source, provide a link to the Creative Commons license, and indicate if changes were made.

\section{References}

Papers of particular interest, published recently, have been highlighted as:

• Of major importance

1. U.S. Global Change Research Program. Climate change impacts in the United States: U.S. national climate assessment. 2014.

2. Pachauri RK, IPCC, editors. Climate change 2007: contribution of ... to the fourth assessment report of the Intergovernmental Panel on Climate Change. 4: Synthesis report: [a report of the Intergovernmental Panel on Climate Change]. Geneva: IPCC; 2008. $103 \mathrm{p}$.

3. Luber G, Knowlton K, Balbus J, Frumkin H, Hayden M, Hess J, et al. Ch. 9: Human Health. Climate change impacts in the United States: The Third National Climate Assessment. 2014 [cited 2017 Mar 23]; Available from: doi:https://doi.org/10.7930/J0PN93H5.

4. Ciesielski T. Climate change and public health: a small frame obscures the picture. NEW Solut J Environ Occup Health Policy 2017 Jan 31; 104829111769107.

5.• Watts N, Adger WN, Ayeb-Karlsson S, Bai Y, Byass P, CampbellLendrum D, et al. The Lancet Countdown: tracking progress on health and climate change. The Lancet. 2017;389(10074):115164. The Lancet Countdown aims to track and report annually on key indicators that reflect progress and setbacks on health and climate change.

6. U.S. Global Change Research Program (2009- ). The impacts of climate change on human health in the United States: a scientific assessment. 2016.

7. Costello A, Abbas M, Allen A, Ball S, Bell S, Bellamy R, et al. Managing the health effects of climate change. Lancet. 2009 May;373(9676):1693-733. https://doi.org/10.1016/S01406736(09)60935-1.

8. Leiserowitz A, Maibach E, Roser-Renouf C, Rosenthal S, Cutler S. Climate change in the American mind: November 2016. Yale University and George Mason University. New Haven, CT: Yale Program on Climate Change Communication; 2017.

9. Zaltman G. How customers think: essential insights into the mind of the market. Harvard Business Press; 2003. 356 p.

10. Bain PG, Milfont TL, Kashima Y, Bilewicz M, Doron G, Garðarsdóttir RB, et al. Co-benefits of addressing climate change can motivate action around the world. Nat Clim Chang. 2016 Feb;6(2):154-7. https://doi.org/10.1038/nclimate2814.

11. Maibach EW, Chadwick A, McBride D, Chuk M, Ebi KL, Balbus J. Climate change and local public health in the United States: preparedness, programs and perceptions of local public health department directors. PLoS One. 2008;3(7):e2838.

12. Bedsworth L. Preparing for climate change: a perspective from local public health officers in California. Environ Health Perspect Res Triangle Park. 2009;117(4):617-23. https://doi.org/10.1289/ ehp.0800114.

13. Carr JL, Sheffield PE, Kinney PL. Local preparedness for climate change among local health department officials in New York State: a comparison with national survey results. J Public Health Manag
Pract JPHMP 2012; 18(2):E24-E32, DOI: https://doi.org/10.1097/ PHH.0b013e31823dea74.

14. Syal SS, Wilson RS, Crawford JM, Lutz J. Climate change and human health - what influences the adoption of adaptation programming in the United States public health system? Mitig Adapt Strateg Glob Change. 2011;16(8):911-24. https://doi.org/10.1007/ s11027-011-9302-1.

15. Polivka BJ, Chaudry RV, Mac CJ. Public health nurses' knowledge and attitudes regarding climate change. Environ Health Perspect Res Triangle Park. 2012;120(3):321-5.

16. Roser-Renouf C, Maibach EW, Li J. Adapting to the changing climate: an assessment of local health department preparations for climate change-related health threats, 2008-2012. PLoS One. 2016;11(3):e0151558. https://doi.org/10.1371/journal.pone. 0151558.

17. Paterson JA, Ford JD, Ford LB, Lesnikowski A, Berry P, Henderson J, et al. Adaptation to climate change in the Ontario public health sector. BMC Public Health. 2012;12(1):452. https:// doi.org/10.1186/1471-2458-12-452.

18. Sarfaty M, Mitchell M, Bloodhart B, Maibach EW. A survey of African American physicians on the health effects of climate change. Int J Environ Res Public Health. 2014;11(12):12473-85. https://doi.org/10.3390/ijerph111212473.

19. Sarfaty M, Bloodhart B, Ewart G, Thurston GD, Balmes JR, Guidotti TL, et al. American Thoracic Society member survey on climate change and health. Ann Am Thorac Soc. 2015;12(2):274 8. https://doi.org/10.1513/AnnalsATS.201410-460BC.

20. Sarfaty M, Kreslake JM, Casale TB, Maibach EW. Views of AAAAI members on climate change and health. J Allergy Clin Immunol Pract Amst. 2016;4(2):333-5. https://doi.org/10.1016/j. jaip.2015.09.018.

21. Purcell R, McGirr J. Preparing rural general practitioners and health services for climate change and extreme weather. Aust J Rural Health. 2014;22(1):8-14.

22. Hawkins IW, Balsam AL, Goldman R. A survey of registered dietitians' concern and actions regarding climate change in the United States. Front Nutr [Internet]. 2015 Jul 8 [cited 2017 Mar 23];2. Available from: http://www.ncbi.nlm.nih.gov/pmc/articles/ PMC4495332/

23. Nigatu AS, Asamoah BO, Kloos H. Knowledge and perceptions about the health impact of climate change among health sciences students in Ethiopia: a cross-sectional study. BMC Public Health. 2014;14(1):587. https://doi.org/10.1186/1471-2458-14-587.

24. Majra J, Acharya D. Protecting health from climate change: preparedness of medical interns. Indian J Community Med. 2009;34(4):317-20. https://doi.org/10.4103/0970-0218.58390.

25. McIver LJ, Chan VS, Bowen KJ, Iddings SN, Hero K, Raingsey PP. Review of climate change and water-related diseases in Cambodia and findings from stakeholder knowledge assessments. Asia Pac J Public Health. 2016;28(2_suppl):49S-58S. https://doi.org/10.1177/ 1010539514558059.

26. Xiao J, Fan W, Deng Y, Li S, Yan P. Nurses' knowledge and attitudes regarding potential impacts of climate change on public health in central of China. Int J Nurs Sci. 2016;3(2):158-61.

27. Wei J, Hansen A, Zhang Y, Li H, Liu Q, Sun Y, et al. Perception, attitude and behavior in relation to climate change: a survey among CDC health professionals in Shanxi province, China. Environ Res. 2014;134:301-8. https://doi.org/10.1016/j.envres.2014.08.006.

28. Tong MX, Hansen A, Hanson-Easey S, Xiang J, Cameron S, Liu Q, et al. Perceptions of capacity for infectious disease control and prevention to meet the challenges of dengue fever in the face of climate change: a survey among CDC staff in Guangdong Province, China. Environ Res. 2016;148:295-302. https://doi.org/10.1016/j. envres.2016.03.043.

29. Semenza JC, Suk JE, Estevez V, Ebi KL, Lindgren E. Mapping climate change vulnerabilities to infectious diseases in Europe. 
Environ Health Perspect. 2012;120(3):385-92. https://doi.org/10. 1289/ehp.1103805.

30. Berry P, Clarke K, Pajot M, Hutton D, Verret M. The role of risk perception and health communication in adapting to the health impacts of climate change in Canada. Nat Resour Can [Internet]. 2009 [cited 2017 Mar 24]; Available from: http://www.climateaccess.org/ sites/default/files/Berry_The\%20Role\%20of\%20Risk\% 20Perception\%20and\%20Health\%20Communication.pdf

31. Akerlof K, DeBono R, Berry P, Leiserowitz A, Roser-Renouf C, Clarke K-L, et al. Public perceptions of climate change as a human health risk: surveys of the United States, Canada and Malta. Int J Environ Res Public Health. 2010;7(6):2559-606. https://doi.org/ 10.3390/ijerph7062559.

32. Ostapchuk J, Harper S, Willox AC, Edge VL, Government RIC. Exploring elders' and seniors' perceptions of how climate change is impacting health and well-being in Rigolet, Nunatsiavut. Int J Indig Health. 2012;9(2):6-24.

33. Cardwell FS, Elliott SJ. Making the links: do we connect climate change with health? A qualitative case study from Canada. BMC Public Health. 2013;13(1):208. https://doi.org/10.1186/1471-245813-208.

34. Semenza JC, Ploubidis GB, George LA. Climate change and climate variability: personal motivation for adaptation and mitigation. Environ Health. 2011;10(1):46. https://doi.org/10.1186/1476069X-10-46.

35. Akerlof KL, Delamater PL, Boules CR, Upperman CR, Mitchell CS. Vulnerable populations perceive their health as at risk from climate change. Int J Environ Res Public Health. 2015 Dec 4;12(12):15419-33. https://doi.org/10.3390/ijerph121214994.

36. Stoutenborough JW, Vedlitz A, Xing X. Are all risk perceptions created equal? Comparing general risk assessments and specific risk assessments associated with climate change. Hum Ecol Risk Assess Int J. 2016;22(1):50-70. https://doi.org/10.1080/10807039. 2015.1054924.

37. Maibach EW, Kreslake JM, Roser-RenoufC, Rosenthal S, Feinberg G, Leiserowitz AA. Do Americans understand that global warming is harmful to human health? Evidence from a national survey. Ann Glob Health. 2015;81(3):396-409. https://doi.org/10.1016/j.aogh. 2015.08.010.

38. Akompab DA, Peng B, Williams S, Saniotis A, Walker IA, Augoustinos M. Climate change, community understanding and emotional responses to the impacts of heat waves in Adelaide. Int J Clim Change Impacts Responses. 2013;4(2):109-26.

39. Rawlins SC, Chen A, Rawlins JM, Chadee DD, Legall G. A knowledge, attitude and practices study of the issues of climate change/ variability impacts and public health in Trinidad and Tobago, and St Kitts and Nevis. West Indian Med J. 2007;56(2):115-21.

40. Abrahamson V, Wolf J, Lorenzoni I, Fenn B, Kovats S, Wilkinson $\mathrm{P}$, et al. Perceptions of heatwave risks to health: interview-based study of older people in London and Norwich, UK. J Public Health. 2009;31(1):119-26. https://doi.org/10.1093/pubmed/ fdn 102 .

41. Mayala BK, Fahey CA, Wei D, Zinga MM, Bwana VM, Mlacha T, et al. Knowledge, perception and practices about malaria, climate change, livelihoods and food security among rural communities of central Tanzania. Infect Dis Poverty. 2015;4(1):21. https://doi.org/ 10.1186/s40249-015-0052-2.

42. Armah FA, Luginaah I, Yengoh GT, Hambati H, Chuenpagdee R, Campbell G. Analyzing the relationship between objective-subjective health status and public perception of climate change as a human health risk in coastal Tanzania. Hum Ecol Risk Assess Int J. 2015;21(7):1936-59. https://doi.org/10.1080/10807039.2014. 1003203.

43. Haque MA, Yamamoto SS, Malik AA, Sauerborn R. Households' perception of climate change and human health risks: a community perspective. Environ Health. 2012;11(1) https://doi.org/10.1186/ 1476-069X-11-1.

44. Kabir MI, Rahman MB, Smith W, Lusha MAF, Azim S, Milton AH. Knowledge and perception about climate change and human health: findings from a baseline survey among vulnerable communities in Bangladesh. BMC Public Health. 2016;16(1):266. https:// doi.org/10.1186/s12889-016-2930-3.

45. Bai L, Cirendunzhu P, Dawa WA, Liu X, et al. Rapid warming in Tibet, China: public perception, response and coping resources in urban Lhasa. Environ Health. 2013;12(1):71. https://doi.org/10. 1186/1476-069X-12-71.

46. Mishra SR, Bhandari PM, Issa R, Neupane D, Gurung S, Khanal V. Climate change and adverse health events: community perceptions from the Tanahu district of Nepal. Environ Res Lett. 2015;10(3): 034007. https://doi.org/10.1088/1748-9326/10/3/034007.

47. Rocklöv J, Bao Giang K, Van Minh H, Ebi K, Nilsson M, Sahlen K$\mathrm{G}$, et al. Special issue: climate change and health in Vietnam. Glob Health Action [Internet]. 2014 Dec 8 [cited 2017 Mar 24];7. Available from: http://www.ncbi.nlm.nih.gov/pmc/articles/ PMC4265652/

48. Asekun-Olarinmoye E, Bamidele JO, Odu OO, Olugbenga-Bello AI, Abodunrin OL, Adebimpe WO, et al. Public perception of climate change and its impact on health and environment in rural southwestern Nigeria [Internet]. Research and Reports in Tropical Medicine. 2014 [cited 2017 Mar 23]. Available from: https://www. dovepress.com/public-perception-of-climate-change-and-itsimpact-on-health-and-envir-peer-reviewed-fulltext-article-RRTM

49. Maibach EW, Nisbet M, Baldwin P, Akerlof K, Diao G. Reframing climate change as a public health issue: an exploratory study of public reactions. BMC Public Health. 2010;10(1):299. https://doi. org/10.1186/1471-2458-10-299.

50. Myers TA, Nisbet MC, Maibach EW, Leiserowitz AA. A public health frame arouses hopeful emotions about climate change. Clim Chang. 2012 Aug 1;113(3-4):1105-12. https://doi.org/10.1007/ s10584-012-0513-6.

51. McCright AM, Charters M, Dentzman K, Dietz T. Examining the effectiveness of climate change frames in the face of a climate change denial counter-frame. Top Cogn Sci. 2016;8(1):76-97.

52. Bernauer T, McGrath LF. Simple reframing unlikely to boost public support for climate policy. Nat Clim Chang. 2016;6(7):680-3. https://doi.org/10.1038/nclimate2948.

53. Hart PS, Nisbet EC. Boomerang effects in science communication: how motivated reasoning and identity cues amplify opinion polarization about climate mitigation policies. Commun Res. 2012;39(6):701-23. https://doi.org/10.1177/0093650211416646.

54. Kreslake JM, Price KM, Sarfaty M. Developing effective communication materials on the health effects of climate change for vulnerable groups: a mixed methods study. BMC Public Health. 2016;16(1):946. https://doi.org/10.1186/s12889-016-3546-3.

55. Connor P, Harris E, Guy S, Fernando J, Shank DB, Kurz T, et al. Interpersonal communication about climate change: how messages change when communicated through simulated online social networks. Clim Chang. 2016;136(3-4):463-76. https://doi.org/10. 1007/s10584-016-1643-z.

56. Asensio OI, Delmas MA. Nonprice incentives and energy conservation. Proc Natl Acad Sci. 2015 Feb 10;112(6):E510-5. https:// doi.org/10.1073/pnas.1401880112.

57. Levine AS, Kline R. A new approach for evaluating climate change communication. Clim Change. 2017;142(1-2):301-309.

58. Walker BJA, Kurz T, Russel D. Towards an understanding of when non-climate frames can generate public support for climate change policy. Environ Behav 2017; 0013916517713299 , 001391651771329 , DOI: https://doi.org/10.1177/ 0013916517713299 . 
59. The Future of Public Health [Internet]. Washington, D.C.: National Academies Press; 1988 [cited 2017 Mar 31]. Available from: http:// www.nap.edu/catalog/1091

60. Frumkin H, McMichael AJ. Climate Change and Public health. Am J Prev Med. 2008;35(5):403-10.

61. Haines A, McMichael AJ, Smith KR, Roberts I, Woodcock J, Markandya A, et al. Public health benefits of strategies to reduce greenhouse-gas emissions: overview and implications for policy makers. Lancet. 2009 Dec 19;374(9707):2104-14. https://doi.org/ 10.1016/S0140-6736(09)61759-1.

62. Laaser U, Dorey S, Nurse J. A plea for global health action bottomup. Front Public Health [Internet]. 2016 Oct 31 [cited 2017 Mar 24];4. Available from: http://www.ncbi.nlm.nih.gov/pmc/articles/ PMC5086808/

63. Lavey WG. Hospitals should help communities prepare for climate change. Am J Public Health. 2016;106(11):1952-4. https://doi.org/ 10.2105/AJPH.2016.303436.

64. Ebi KL, Semenza JC. Community-based adaptation to the health impacts of climate change. Am J Prev Med. 2008;35(5):501-7. https://doi.org/10.1016/j.amepre.2008.08.018.

65. Mayhew S, Belle SV, Hammer M. Are we ready to build health systems that consider the climate? J Health Serv Res Policy. 2014;19(2):124-7. https://doi.org/10.1177/1355819613516943.

66. Schmidt A, Ivanova A, Schäfer MS. Media attention for climate change around the world: a comparative analysis of newspaper coverage in 27 countries. Glob Environ Change. 2013;23(5): 1233-48. https://doi.org/10.1016/j.gloenvcha.2013.07.020.
67. Nisbet MC, Price S, Pascual-Ferra P, Maibach E. Communicating the public health relevance of climate change: a news agenda building analysis. Sci Commun [Internet]. 2010 [cited 2017 Mar 24]; Available from: https://www.researchgate.net/profile/Edward Maibach/publication/242451772_Communicating_the_Public Health_Relevance_of_Climate_Change_A_News_Agenda Building_Analysis/links/02e7e52d3f193c143c000000.pdf

68. Weathers MR. Newspaper coverage of global warming and climate change (GWCC) as a public health issue. Appl Environ Educ Commun. 2013;12(1):19-28.

69. Koh H. Communicating the health effects of climate change. JAMA. 2016;315(3):239-40. https://doi.org/10.1001/jama.2015. 18271.

70. Patz JA. Solving the global climate crisis: the greatest health opportunity of our times? Public Health Rev. 2016;37(1):30. https://doi. org/10.1186/s40985-016-0047-y.

71. Adlong W, Dietsch E. Environmental education and the health professions: framing climate change as a health issue. Environ Educ Res. 2015 Jul 4;21(5):687-709. https://doi.org/10.1080/13504622. 2014.930727.

72. Ansolabehere S. Cheap and clean: how Americans think about energy in the age of global warming. Cambridge, Massachusetts: MIT Press; 2014. 261 p.

73. DeCicco J, Yan T, Keusch F, Muñoz DH, Neidert L. U.S. consumer attitudes and expectations about energy. Energy Policy. 2015 Nov;86:749-58. https://doi.org/10.1016/j.enpol.2015.08.022. 